\title{
COMMUNITY BASED APPROACH FOR SOLID WASTE MANAGEMENT IN KHULNA CITY
}

\author{
R. Ahasan* \\ URP Discipline, Khulna University, Khulna, Bangladesh \\ "Corresponding Author: rakibukahasan@gmail.com
}

\begin{abstract}
Generation of solid waste (SW) is a major problem in urban areas, thus its management is one of the important obligatory functions to not only urban local authority but also for the inhabitants. The citizens expressed their concerns about the waste management system in KCC and associated problems that they are encountering. Waste generation in Khulna City Corporation is around 455 tons of municipal solid waste/day and generation rate is now $0.75 \mathrm{Kg} / \mathrm{capita} /$ day on an average. Existing public utility services and facilities are not adequate to meet the demand of disposing these massive amount of wastes and that's why several problems are arising. There are some deterrents in the KCC's solid waste Management system, arising from both the city corporation authority and the citizen of different levels. With a view to address the problem from through community participation, this paper intends to evaluate the potential of community based solid waste management approach in context of Khulna city.
\end{abstract}

Keywords: Solid Waste; solid waste management; community based solid waste management

\section{INTRODUCTION}

For most of the cities in developing countries also for the countries which are comparatively developed, massive production and solid waste disposal is a substantial reason for the environmental degradation. According to the KCC Ordinance, 1984, KCC is responsible for collection, transportation, and treatment of solid waste in Khulna City (Murtaza, 2002). But having problems and constraints with availability of resources, administrative constraints and other relevant, the organization has not been able to manage well entirely the whole task of solid waste disposal. And as such, it has become a major concern for the city authorities as well as the city dwellers since the problem relating to the solid waste disposal directly and indirectly affect the health and hygienic conditions of the city people. Waste generation rate of $\mathrm{KCC}$ is now $0.50 \mathrm{~kg} / \mathrm{cap} /$ day producing around 950 tons of wastes, where about $36.84 \%$ being uncollected (Riyad, 2014). The rubbishes, which remain uncollected, are dumped in open spaces, street and drains, clogging the drainage system, which create serious environmental degradation and treats to health. Public awareness, political determination and public participation are essential for the successful implementation of the legal provisions and to have an integrated approach towards sustainable management of municipal solid wastes in the city as well as in the country.

\section{METHODOLOGY}

This work has done basically based on secondary data from sources like Conservancy department of KCC, NGOs working in SWM System. The work process also involves observational study which guides the evaluation of current situation and identification of the causes responsible.

\section{Existing Scenario}

The major sources of solid wastes in Khulna are residences, whole and retail sale market places including shopping places, streets, hotels and restaurants, private clinics and hospitals, educational institutions, cinemas, railway, bus, and launch/steamer Ghats, slaughter houses, etc. In a study by Ahmed (1991) in Bangladesh, it has been found that during wet season the waste generation rate increases by $15 \%$ to $50 \%$. Table 1 depicts that solid waste generation in Khulna city is growing with the growth of population.

The composition of solid waste varies according to location, level of income and standard of living of the households/people, energy sources and season. The quantity of waste generation increases during the rainy season, when many people eat vegetables and fruits such as mangoes and jackfruits. 
Table 1: Solid waste generation in Khulna city

\begin{tabular}{cccccc}
\hline Year & $\begin{array}{c}\text { Population } \\
\text { (million) }\end{array}$ & $\begin{array}{c}\text { Waste Generation } \\
\text { Rate (kg/day/capita) }\end{array}$ & $\begin{array}{c}\text { Total } \\
\text { generation } \\
\text { (tones/day) }\end{array}$ & $\begin{array}{r}\text { Waste } \\
\text { Collection } \\
\text { (tones/day) }\end{array}$ & $\begin{array}{r}\text { Collection } \\
\text { Efficiency }(\%)\end{array}$ \\
\hline 2008 & 1.5 & 0.35 & 525 & 275 & 52.38 \\
\hline 2013 & 1.8 & 0.50 & 950 & 600 & 63.16 \\
\hline
\end{tabular}

(Source: Conservancy section, KCC, 2013)

Table 2 indicates some major sources and characteristics of solid waste in Khulna city. It has been observed that $70-80$ per cent of the generated waste are organic in nature and these are easily bio-degradable. And the rest $30-20$ per cent of the total waste generated are inorganic and non-biodegradable.

Table 2: Sources and Characteristics of Solid Waste in Khulna city

\begin{tabular}{lll}
\hline Source/Type & Unit & Quantity Produced \\
\hline Domestic & $\mathrm{Kg} /$ day/Household & $1.0-0.5$ \\
\hline Retail sale market & $\mathrm{Kg} /$ day & $50-200$ \\
\hline Slaughter house & Tones/day & $2-3.5$ \\
\hline Hotels and restaurants & $\mathrm{Kg} /$ day & $50-150$ \\
\hline
\end{tabular}

(Source: Environmental Risk Management Action Plan for Khulna City, 2000)

Conservancy Department of KCC is responsible for the collection, transportation/removal and disposal of solid waste in Khulna city. Recently, in some parts of Khulna city NGOs have introduced door-to-door collection of solid waste. But neither communal bin system coverage nor house -to-house waste collection system is adequate yet. $\mathrm{KCC}$ is liable for the operation and maintenance of municipal services, including solid waste management.

\section{Evaluation of Existing Situation}

- Solid waste generation has increased steadily over as a result of higher consumption and greater packaging of goods. The rate is variable due to seasonal availability of fruit and vegetables and the occurrence of festivals.

- Currently, housewives or maid servants dispose of waste up to six times a day. It is frequently dumped indiscriminately due to a lack of roadside bins or bins being in a poor condition (low-income areas), bins used a variety of participatory methods being surrounded by waste or too far away and socially unsafe for maid servants to use (higher income areas). Hawkers (itinerant waste buyers) frequently call on householders to collect valuable emerged waste (e.g. paper, metal, plastics) for which they either make a small cash payment or pay in kind.

- A lot of waste is dumped in drains causing floods in the rainy season.

- There is no regular time for collection from the roadside waste bins by KCC trucks.

\section{Existing Management System}

Eight (8) functional departments and the conservancy department of Khulna City Corporation is liable for management, maintenance and monitoring of solid waste, street sweeping, public latrine and urinal, drain sludge, and street lighting. A total of 22 NGOs and CBOs are involved in MSW management in different wards of $\mathrm{KCC}$ in cooperation with the city authority and respective ward Commissioner (Riyad, 2014).

\section{Problems with Existing SWM System}

Existing system of solid waste management is problematic due to some certain causes which can be drawn from different stakeholder's perspective i.e. from community perspective and from the management authority's perspective.

Community identified the following problems with the present solid waste management system:

- Lack of awareness of waste disposal and environmental sanitation at household level. Also no awareness creation at community level;

- Insufficient roadside bins which are often broken. Scattering of waste from bins by dogs.

Khulna City Corporation (KCC) identified the following problems with the present solid waste management system: 
- Lack of public awareness (e.g. dumping waste in drains etc.);

- Lack of community cooperation;

- Lack of funding (irregular payment of taxes by the citizens, insufficient government funds);

- Inadequate logistics;

- Lack of manpower and equipment which causing irregular disposal of wastes;

- Poor supervision of KCC staff and a feeling of job insecurity.

The NGOs and CBOs related with the solid waste management system has identified the following problems with the present system:

- Fixed time for waste collection not properly maintained;

- Involvement of children in collection of waste;

- Absence or irregular medical check-up facilities for people involved in waste collection and removal;

- Absence of legal status of involving authorities in solid waste management;

- Lack of co-operation among the organizations;

- Issue of sustainability of activities not seriously considered.

\section{Behavioural Causes of the Problem}

Some oblivious and hasty human activities are also responsible for the mismanagement and problems with the existing solid waste management system alongside the problems in the KCC or NGO level. These can be categorized as-

- Low or absence of motivation and irrational behavior;

- Lack of sense of responsibility to the society;

- Lack of social coherence and absence of community initiatives;

- Impassive to travel for dumping;

- Irregular payment of service charges;

- Absenteeism of the services of waste pickers/collectors;

- lack of incentive to encourage people to behave and take their waste to point of collection;

- Lack of community \& public awareness;

- Absence of awareness about waste disposal and environmental sanitation in the Household level.

The conventional approach to $S W M$

Waste is generated in the home and usually stored until a small amount has been accumulated. It is the responsibility of the generating household to transport the waste to the nearest road side bin which is provided by the city corporation. The city corporation is responsible for the transfer of this waste from the roadside bins to the final disposal site.

\section{Problems with the conventional approach}

In many cases the city corporation fails to provide a sufficient number of roadside bins or does not position them in convenient occasions or fails to ensure that they are of an appropriate design. As a result, householders may dump the waste in open spaces, drains or simply around roadside bins. Poor motivation for proper waste disposal can be due to low awareness of the hazards of irresponsible solid waste management or social factors that make it unacceptable for certain members of the household to take waste to the roadside bins. Delays in waste collection and transportation to the final disposal site by the city corporation also occur due to institutional or financial problems.

\section{Community Based Approach for SWM}

The city wards are divided into small areas called primary collection blocks in any community based solid waste management approach. These blocks consist of approximately 500 households which are all served by one rickshaw van (WSP, 2000). Waste generated in the home is stored and collected everyday by a primary collector who transports the waste to nearby transfer points, normally in a rickshaw van. This is primary collection and is the responsibility of the community. Transfer points are places where waste is unloaded from primary collection vehicles to be taken away by secondary transport. Several primary collection blocks are served by a transfer point. The waste is then collected from the transfer 
points and taken to the final disposal point by a large truck. This is secondary collection and is the responsibility of the city corporation.

\section{Implementation}

Implementation of community based solid waste management can be done in several phases which will begin the collaboration of community with the city corporation and the collaborator usually the ward commissioner and NGO representative. That will have followed by building community organizations after defining primary collection blocks and lastly operation of primary collection system.

\section{Phase 1: Building Community Organizations}

- First, a community Organization for SWM have to be initiated;

- It will divide the whole community into several blocks for better management (Primary blocks);

- Each block will have a primary collection Point where waste will be dumped by the users (HH, Commercial/Other Users);

- Collection points will be decided by the organizations by negotiating with KCC;

- A primary collection system (collection rickshaw van) will be organized by the committee by the funding of the primary users of the block.

Table 3: Investment cost for primary collection system for one collection block

\begin{tabular}{ll}
\hline ITEMS & COST (BDT) \\
\hline Rickshaw Van & 10,500 \\
\hline Tools & 1,500 \\
\hline Protective clothing & 1,000 \\
\hline TOTAL & 13,000
\end{tabular}

Source: modified and updated from (WSP, 2000)

*Cost may rise up to $2000 \mathrm{BDT}$

This items which will be used for primary collection system is not expensive and not different from communities daily uses. But what is important to notice here is that despite being dependent on the collection system of the city corporation, the community own will do the collection and disposal to the point from where the city corporation will do the secondary collection. Thus, the collaboration will help in decreasing impacts of solid waste mismanagement. Although the source shown is backdated, it was updated in 2014. That's why the data can be said of use.

\section{Phase 2: Operation of Primary Collection System}

- The Primary Collection System will collect the wastes twice a day (or once based on waste generation rate);

- Users will have to bear the operating cost of the system;

- Community Organization will fix the charge for the users of the collection system and will collect the charge as well;

- Charge may vary between different income groups;

- Charges may also be promotional (BDT 5-10), can rise with the change of time.

Table 4: Monthly operating cost of a primary collection system for each collection block

\begin{tabular}{ll}
\hline ITEMS & COST (BDT) \\
\hline Van Drivers salary & 2200 \\
\hline Assistants salary & 800 \\
\hline supervision Cost of SWC & 600 \\
\hline Repair \& Maintenance & 100 \\
\hline Depreciation Cost & 300 \\
\hline Total & 4000 \\
\hline
\end{tabular}

Source: modified and updated from (WSP, 2000)

What's best about this community based approach is that it doesn't cost much after the initial investment to setup the collection system. The maintenance is cheap and per month overall cost is not very much considering the primary collection block do consist of 500 households. Moreover, the 
service provided will be well enough to serve the community, to collect the wastes twice a day and to transport them to the secondary collection point from which city corporation will collect the wastes and dispose it to the final disposal site.

\section{Implementability \& Replicability}

Good thing about this "Community Based Solid Waste Management Approach" is that it's not only a rhetoric idea or concept but it can be easily implemented, replicated in other areas and also scaling up can be done of this approach. Low set up cost and operating cost makes it easy to implement in the community level. Also the maintenance is easy and the system is self-sustaining, so implementation and operation is not an issue to bother. Scaling up can be done if the city corporation adapt the practice in the wide scale in every ward and nationally as well, if other City corporations/ Pourashava use the model as an ideal one.

\section{Management and Legal Support}

To encourage community based solid waste management City Corporation may follow-

- Provide land for use as primary point of waste dumping;

- Collection of waste from primary collection point should strictly be maintained and monitored;

- Encourage involvement of NGOs and CBOs in SWM specially collection from the primary point;

- Shall make adequate arrangements for the removal of refuge from all public streets, public latrines, urinals, drains and all public buildings;

- Establishment of appropriate transfer points and secondary transportation that integrates well with the primary collection system;

- Legal framework to support NGO and CBO involvement should be prepared.

At the same time, City Corporation can also encourage NGO and CBO involvement in the management and disposal system. For the purpose the framework may be as it shown in Figure 1-

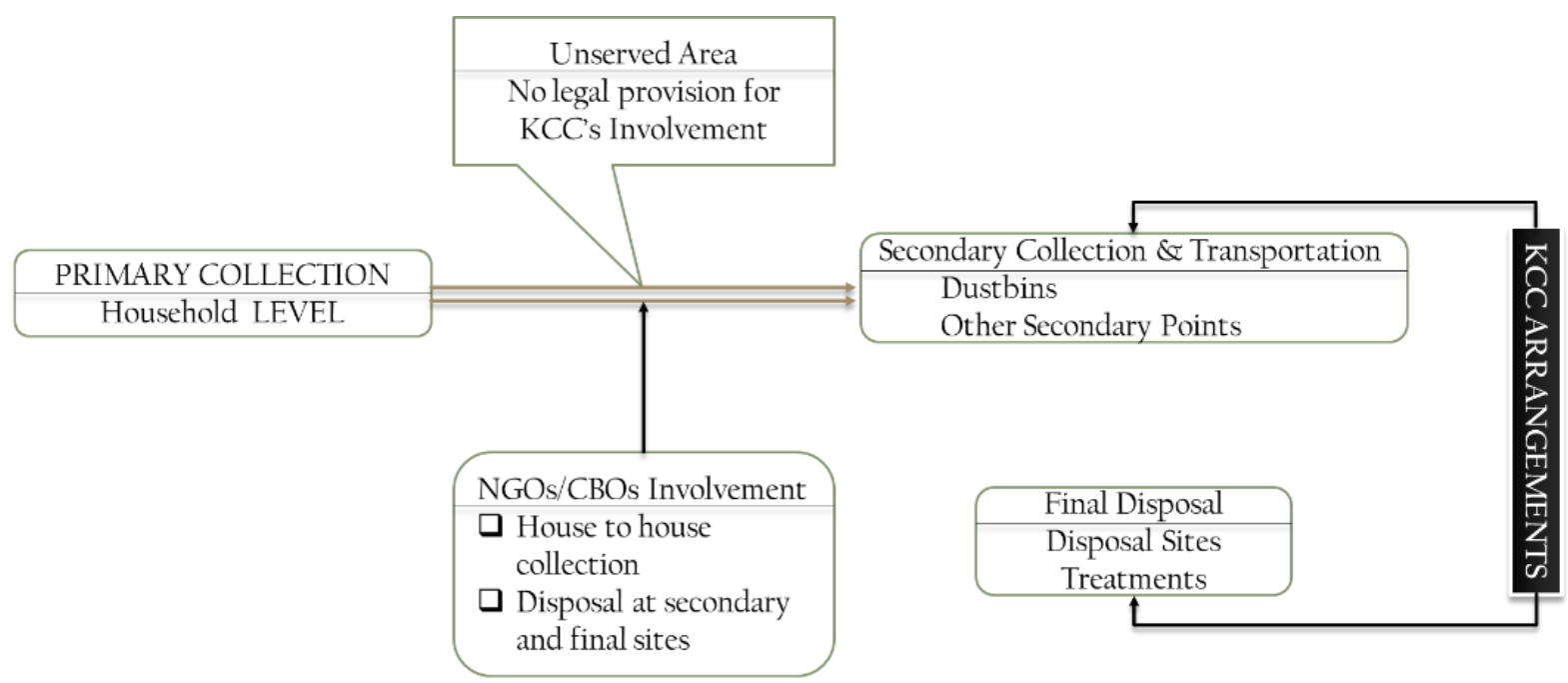

Fig. 1: Framework for NGO involvement (Murtaza, 2002)

\section{CONCLUSION \& REMARKS}

It is evident from some from some previous studies that the city dwellers expressed their concerns about the solid waste management system in KCC and its associated problems that they are encountering. There are some hindrances in the KCC's solid waste Management system. These problems are arising from both the city corporation authority and the citizen of different levels. In most of the cases residents of a neighbourhood have a sense of responsibility for their home and immediate environment, but the public places such as streets and drains are considered the responsibility of the State. Willingness to pay is a rather central point because it is important for the success of a Participatory solid waste management project and it is related to many other aspects such as the motivation of operators and households and the reliability of the service (Rahman, et al., 2005). 
Management of Participatory solid waste services is often a voluntary activity, mostly carried out by the more effluent residents, who are motivated by community benefits such as a cleaner environment, a better health of neighbourhood residents, status of the job, etc. While motivated management is one of the success factors of Participatory solid waste management project, exclusive dependence on one person who manages the operation of a solid waste service is considered undesirable, because accountability to the community and the continuity of the service may not be secured any more.

The salary of operators of waste collection services is often low, because waste collectors derive their income from waste collection fees and from the sale of recyclables. Both do not yield much revenue in low-income neighbourhoods. Fee collection is not high, because households in low-income neighbourhoods are not able to pay high fees. The waste that remains to be collected is often worthless due to its high organic content. Another reason for the low salary of operators of waste collection services is the size of coverage areas, which is often too small to earn an adequate income. The low status of waste collectors in the society may be caused by their low salary, the nature of their work and sometimes by their waste-picker background. The nature of their work is often considered unpleasant and filthy, not only collection but also activities such as sorting of garbage at a composting plant.

Solid waste management scenario in Khulna City Corporation area is being deteriorated day by day as the situation is very difficult to handle the colossal volume of waste in KCC due to the irrepressible migration of rural people to urban areas for better life. Public awareness, political determination and public participation are essential for the successful implementation of the legal provisions and to have an integrated approach towards sustainable management of municipal solid wastes in the country. All the practices and efforts should reflect the better future but practically all the activities are not in planned manner and not to target oriented. As an emerging area, Khulna city should develop in a proper way to make beautiful, liveable town in near future. Proper management and initiatives can lead organized and succeed outputs.

\section{References}

DFID, nd. Success and Sustainability Indicators: A tool to assess primary collection schemes, London: s.n.

Enayetullah, I; Sinha, AMM and Khan, SSA. 2005. Urban Solid Waste Management Scenario of Bangladesh: Problems and Prospects. Dhaka: Waste Concern.

Murtaza, DMG. 2002. SOLID WASTE MANAGEMENT IN KHULNA CITY. Plan Plus, 1(1): 6-15. Rahman, DMM; Salequzzaman, DM; Bahar, MM and Uddin, MN. 2005. People's Perception of the Existing Solid Waste Management of Khulna City Corporation (KCC) Area: A Case Study of Participatory Management. Khulna, Bangladesh Centre for Advanced Studies.

Riyad, A and FSH. 2014. Challenges of Waste Generation \& Improvement of Existing Scenario in Commercial City of Bangladesh. Global Journal of Researches in Engineering: e Civil and Structural Engineering, 14(1):6-12.

Waste Concern, ITN-BUET \& DOE. 2004. SAARC WORKSHOP ON SOLID WASTE MANAGEMENT, Dhaka: s.n.

WSP, 2000. Community Based Pilot Project on Solid Waste Management in Khulna City: General Project Description, Khulna: Swiss Agency for Development and Co-operation.

Zahur, M. 2007. SOLID WASTE MANAGEMENT OF DHAKA CITY: PUBLIC PRIVATE COMMUNITY PARTNERSHIP. BRAC University Journal, IV(2):93-97. 